\title{
The topography of the world by IN-YOU-ZU
}

\author{
Yukihide.AKIYAMA $^{\text {a }}$ Izumi.SAKAMOTO $^{\text {b }}$

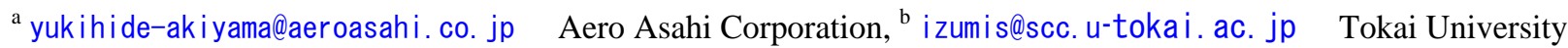

Keywords: Topographic maps, Atlas, Plate boundary,

\begin{abstract}
The map which shows the large-scale topography on the earth is made variously even now. We made a Topographic map as IN-YOU-ZU from topographic data, too. An ambiguous part became easy to judge by a result and conventional expression method. A study of the map world is developed by using IN-YOU-ZU as a background map, and We will think with explication of the topography structure and expect scientific progress. A made Topographic map is using exhibited topographic public data. When more in-depth data can be used, it's expected that the precision of the expressive power rises more. Geographical Survey Institute make the basic mapinformation 5m mesh DEM, 500m mesh water depth data (J-EGG500)by JODC and the data of TOPO1 of World are used for a Topographic map.

Theoretically, it's the Topographic map by which the modelling is put the accent on to add the temperature(cold or warm) color of the difference between the inside of the geomorphic surface mean and the plane where the outside is made the wavelength as the depth (or the height). The one to which the name of the large-scale tectonic forms was attached about the world topographical map is Figure 1. The world topographical map by IN-YOU-ZU.
\end{abstract}

\section{Introduction}

Many maps to which the large-scale topography on the earth is expressed are made even now. Measurement technology improves and data of all over the world is being maintained. The environment that OPEN data can also use, well, This map made a Topographic map as INYOU-ZU from topographic data, too. When a Topographic map was compared, the part ambiguous by conventional expression method could be done closely.

\section{Methods}

Used data is data on the topography shown to below.

Japanese Geographical Survey Institute: the basic mapinformation $5 \mathrm{~m}(10 \mathrm{~m})$ mesh DEM, the whole world by TOPO1 ( $\leqq 1145 \mathrm{mGrid}: 0.016667$ Degree) and Japan Ocean Data Center make the $500 \mathrm{~m}$ mesh water depth data (J-EGG500). Numerical value topographic data(DEM) was calculated and the next was processed. The part more expensive than an average in an area was made warm color. Cold color did a part lower than an average in an area. The modelling is being given as a result. (ICC2015, 2017 is being introduced about a principle of the map.)

\section{Result}

It was possible to make the world topographical map with to add the large-scale terrain name to original IN-YOU$\mathrm{ZU}$ and an emphasized map.

Figure 1. is topographical map by IN-YOU-ZU of the world. Figure 2 . is The plate boundary map. an emphasis figure of the tectonic line. The data with the higher

resolution is being used and figure 3. into which it was expanded partially around Izu-Hakone is being made.

\section{Discussion}

IN-YOU-ZU is often expressing the large-scale topography structure. Figure 1. When using more indepth data so that figure 3. may be compared and understood, you can realize that it's also possible to express microtopography.

\section{Conclusions}

It was introduced to be able to put IN-YOU-ZU to good use as a background Topographic map by this paper.

\section{Reference}

- Growth process of island - case of Nishinoshima Island Takuya Sakai,Yukihide Akiyama, ICC2017.Wasington.USA

- The Earth Surface Topographic Map(IN-YOU-ZU) Seamless Map of Land and Sea bottom around Japan. Yukihide Akiyama, Takuya Sakai, Kouji Omori, Kiyoshi Kumagai. JCA, 53(4),4_10-12,2015

- The earth surface topographic map (IN-YOU-ZU) seamless map of land and sea bottom. Takuya Sakai,

Yukihide Akiyama, ICC 2015. Rio de Janeiro. Brazil

- The application of IN-YOU-ZU for a topographic interpretation, Ryuuichi Sekoguchi. Yukihide Akiyama. Hiroshi Kobayashi. Junichi Takanuki, JGL2007,J171-004

\section{Gratitude}

Data offer engines(Geographical Survey Institute, Japan Coast Guard, JAMSTEC, Atmosphere and Research Institute, the University of Tokyo , Tokiai University, NOAA, NASA, e.t.c.) and the persons who helped us. 


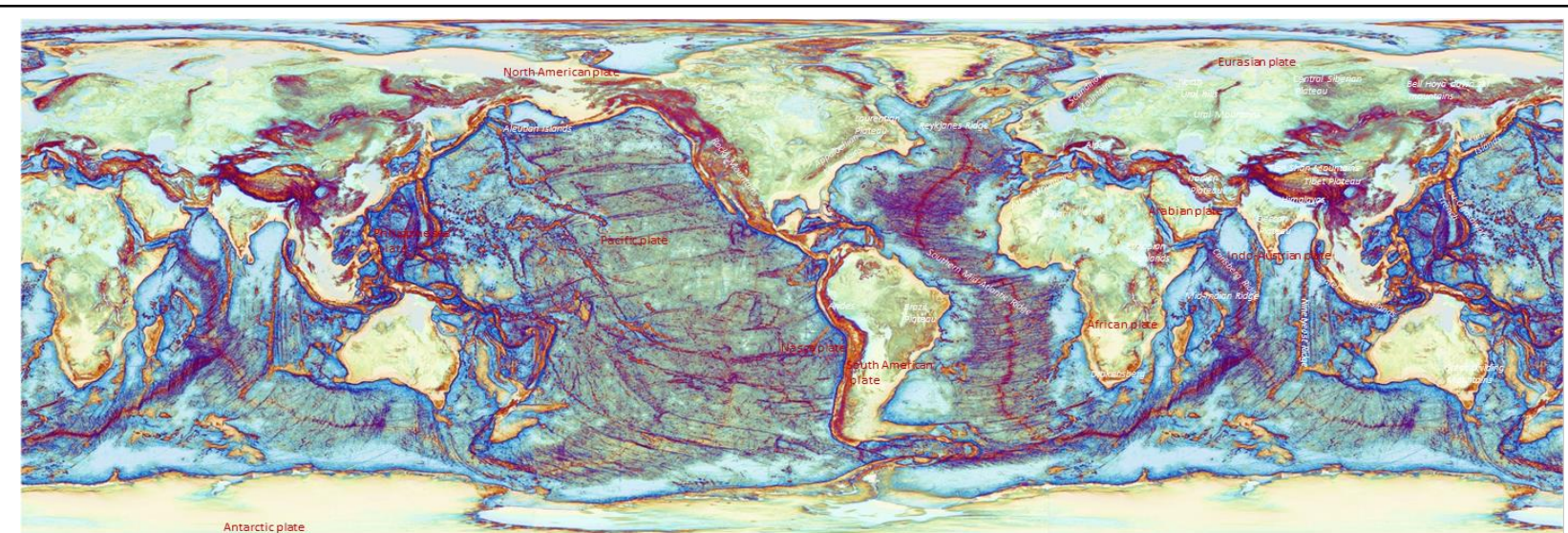

Figure 1. The world topographical map by IN-YOU-ZU (0 degree to 180Degree East to 0degree to 180Degree)

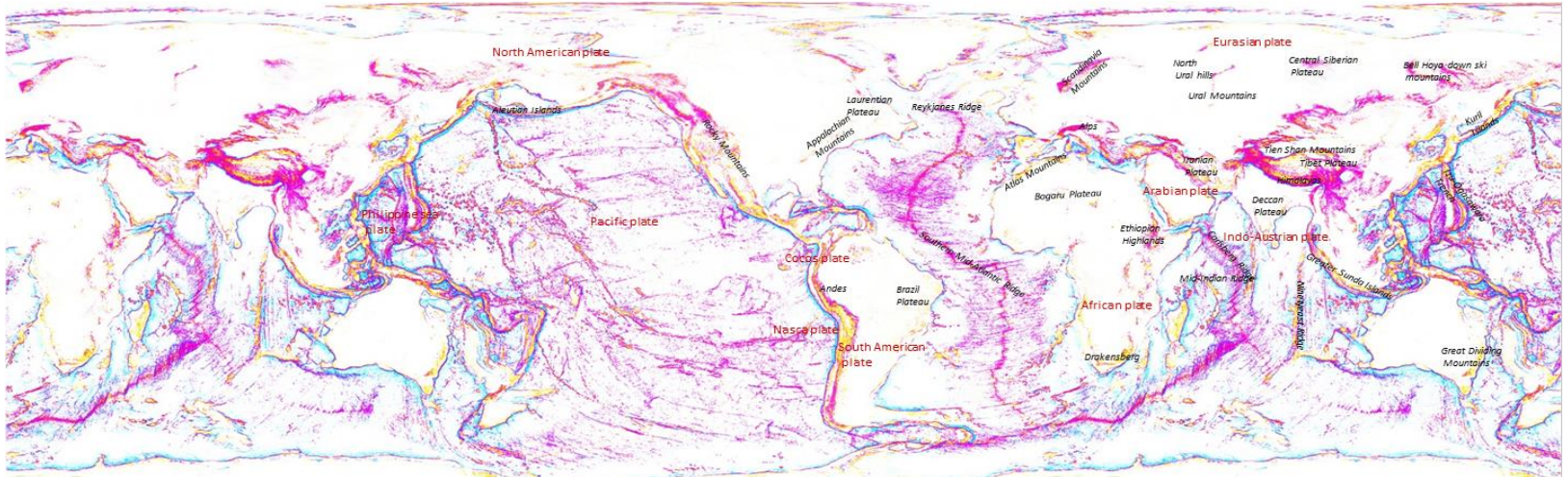

Figure 2. The plate boundary map by contrast stretching : The topography of the world by IN-YOU-ZU

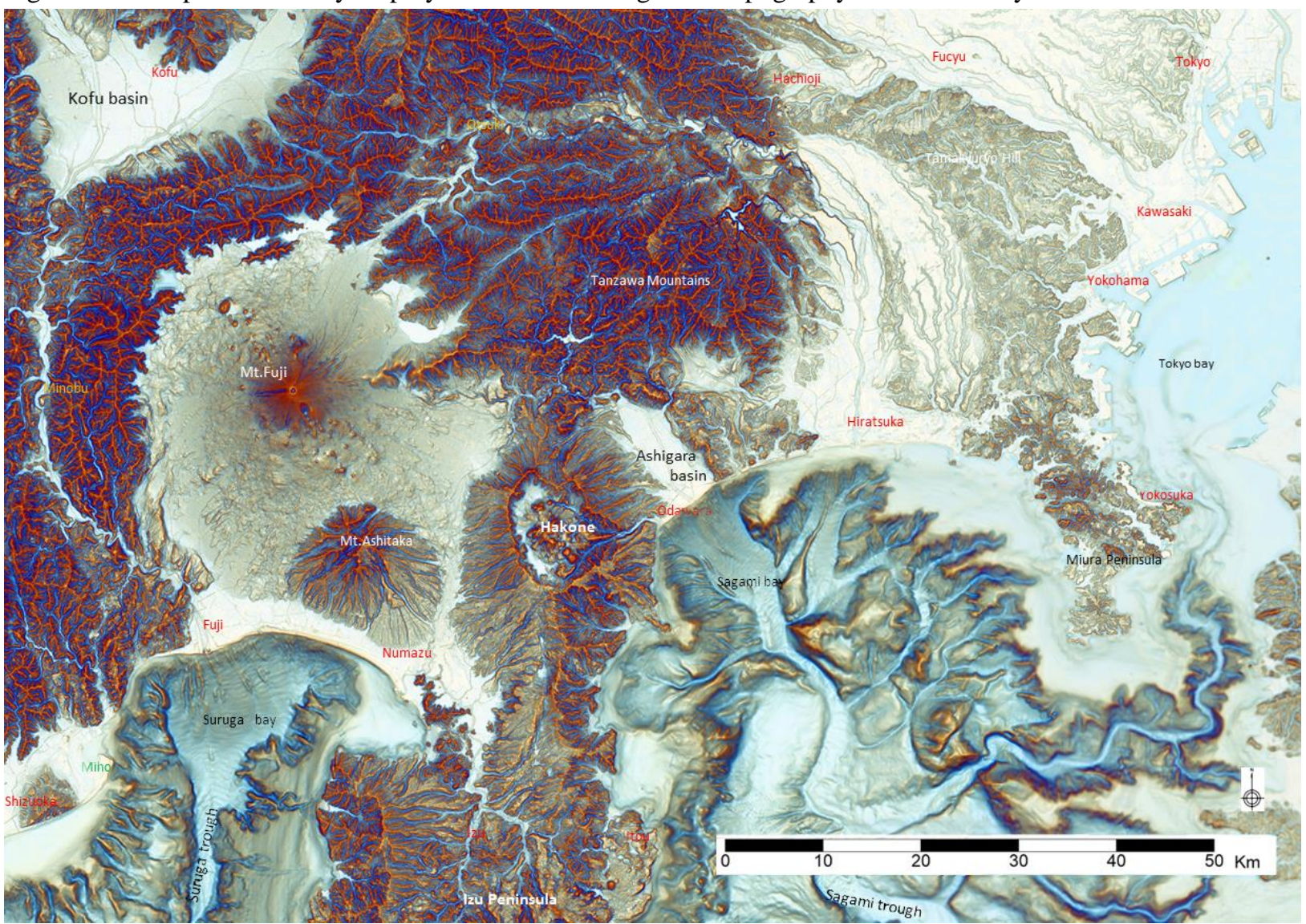

Figure 3. The topography of the around Izu-Hakone by IN-YOU-ZU

(Used data is topo1,5m DEM and J-EGG500,e.t.c.) 